\title{
Commentary
}

"An expert is a person who has made all the mistakes that can be made in a very narrow field."

-Niels Bohr (1885-1962)

Sharing a complication with colleagues is a generous act, demanding time, effort, humility, and intellectual honesty. Knowing how others have dealt with a similar problem can be both useful and comforting for the clinician facing a similar situation.Perhaps even more importantly, there exists the potential to prevent future occurrences of the complication outright. In the present article, "Rare case of a total cranial shunt migration", the authors present a rare complication of ventriculoperitoneal shunting: total intracranial shunt migration..$^{[1]}$ They also provide an advanced solution to the problem, utilizing endoscopic retrieval of the malpositioned shunt. Thankfully, this complication is rare, although the reported occurrence rate of $0.1-0.4 \%$ may come as a surprise to many clinicians who may have never been faced with this complication. ${ }^{[2]}$ Certainly, the images provided by the authors are striking, but there already have been around 60 cases reported in the medical literature. ${ }^{[3]}$

Neurosurgery is a complex discipline that places a multitude of intellectual and technical demands on the human beings holding the scalpel.The key to dealing with the aftermath of any complication is to not lose the lessons it provides. Many other fields have formalized this process of analysis and even have entire publications dedicated to the analysis of errors and complications. For example, the annual publication "Accidents in North American Mountaineering", published by the American Alpine Club, sets out to formally analyze accidents and mishaps in mountaineering. Whenever possible, all involved climbers are interviewed, all technical factors examined, and expert analysis is provided. It has become required reading for professional mountaineers, mountain guides, and serious amateur climbers worldwide. Is it time for a similar publication for neurosurgeons? Whether online or in print form, such a publication would provide a forum where surgeons can share thoughts, analysis, solutions and experience.

Of course, not all complications will undergo the scrutiny of publication in the medical literature. Nonetheless, a regular, systematized census of errors and complications, and analysis of modifiable contributing factors should be part of every neurosurgeon's practice. In many centers, this is performed during the course of "morbidity and mortality" ( $\mathrm{M}$ and $\mathrm{M}$ ) rounds, but even the solo practitioner needs to regularly, dispassionately, and honestly review unexpected and undesired outcomes. This process should be formalized to avoid neglecting possible contributing factors. The field of Root Cause Analysis has furnished us with several tools, such as the "fishbone technique", which involves systematically examining individual factors, patient factors, task-specific factors, education and training, team and social factors, working conditions, equipment and resources, communication, and organizational and strategic factors, and their contributions to the final outcome. ${ }^{[4]}$

What are the mechanisms of intracranial shunt migration? Proposed mechanisms include high intraabdominal pressures, peristaltic movements, intermittent obstruction, pressure buildup in the valve pocket leading to a buildup of backpressure, and repeated flexion/extension movements contributing to a "windlass" mechanism of shunt tubing retraction..$^{[5-9]}$ Are there identifiable and/or modifiable risk factors predisposing to this complication? Factors that have been proposed include the use of a hard or spring-loaded shunt valve, lack of a shunt chamber or a unishunt design, shunt component disconnection, adhesions, necrosis, a short shunt length (such as in pediatric patients), and a large burr hole. ${ }^{[5,7,8,10]}$

In the end, what can neurosurgeons do to minimize the occurrence of this complication? The relative paucity of reported cases may preclude definitive answers, but paying attention to certain technical details seems prudent. Keeping the burr hole size smaller than the shunt valve diameter is one obvious strategy, although this might be difficult with some shunt designs. Using clips or sutures to anchor both the valve and peritoneal ends of the catheter is another common strategy, although this by no means guarantees against shunt migration. ${ }^{[10]}$ When using a contour-style valve, I will typically suture the valve to the pericranium to guard against migration. Other proposed strategies include using a cruciate as opposed to a linear dural incision, the use of burr hole covers for large bony openings, and the application of a pressure dressing to the site of the subcutaneous valve pocket to prevent the development of an enlarged cerebrospinal fluid-containing pocket. ${ }^{[6,11]}$ The actual effectiveness of these strategies is unknown.

How should this complication be dealt with? Sometimes the safest way to deal with an isolated retained ventricular catheter is to leave the catheter in situ, but in the case of an 
entire shunt, removal seems prudent in most cases, and in the setting of shunt infection is mandatory in virtually all cases. Endoscopy, as described by the authors, provides an excellent tool for the job, allowing direct visualization of the shunt and surrounding structures, with minimal intrusion into the cranial cavity. In cases where finding the shunt proves challenging, adjuncts such as fluoroscopy, or image guidance can be considered. ${ }^{[3]}$

Complications are an integral and unavoidable part of surgical practice, and should not necessarily be viewed as a source of embarrassment or a mark of inferiority. What is unconscionable, however, is to fail to learn from our complications.

\section{David A Omahen}

Department of Surgery, Division of Neurosurgery, Royal Inland Hospital, Suite 212, 300 Columbia Street, Kamloops, British Columbia, Canada

Address for correspondence: Dr. David A. Omahen, Division of Neurosurgery, Royal Inland Hospital, Suite 212, 300 Columbia Street, Kamloops, British Columbia, Canada. E-mail: domahen@ualberta.ca

\section{References}

1. Naik V, Phalak M, Chandra S. Rare case of a total intracranial shunt migration. J Neurosci Rural Pract.2013;4:95-6

2. Acharya R, Bhutani A, Saxena H, Madan VS. Complete migration of ventriculoperitoneal shunt into the ventricle. Neurol Sci 2002;23:75-7.

3. Herbowski L, Szydlowska R, Rudnicki J, Harat A, Sagan L. Fluroscopyneuro-guided endoscopic removal of a lost ventricular catheter in a hydrocephalic girl with staphylococcal shunt infection. Open J Modern Neurosurg 2012;2:50-3.

4. World Health Organization. Patient Safey Workshop: Learning From Error.1-26. Available from: http://www.who.int/patientsafety/activities/ technical/vincristine_learning-from-error.pdf. [Last accessed on 2012 Jul 30].

5. Gupta PK, Mann KS. Shunt migration into a Dandy Walker cyst. Neurol India 2000;48:89-90.

6. Fransen P, Kevenk U, Thauvoy C. Subcutaneous cranial migration of a ventriculo peritoneal shunt. Turk Neurosurg 1994;4:38-40.

7. Thauvoy C, Kallel S, Marion B, Scholtes JL, Stroobandt G. Unusual complication of peritoneal drainage: Migration of a shunt in the subdural space. Childs Nerv Syst 1989;5:47-9.

8. Cerron-Rojas VR, Vega-Basulto S, Varela-Hernandez A, Montejo-Montejo J, Gutierrez-Munoz FG. Simultaneous cephalic migration of a ventriculoperitoneal shunt into the intraventricular and subdural spaces. A case report. Rev Neurol 2001;33:437-9.

9. Agarwal A, Kakani A. Total migration of a ventriculo-peritoneal shunt catheter into the ventricles. J Pediatr Neurosci 2011;6:88-9.

10. Eljamel MS, Sharif S, Pidgeon CN. Total intraventricular migration of unisystemventriculo-peritoneal shunt. Acta Neurochir (Wien) 1995;136:217-8.

11. Komolafe E, Adeolu A, Komolafe M. Complete intraventricular migration of a ventriculo-peritoneal shunt- a case report and brief literature review. Afr J Neurol Sci 2007;26:69-74.

\begin{tabular}{|l|l|}
\hline \multicolumn{2}{|c|}{ Access this article online } \\
\hline Quick Response Code: & \\
\hline$\square$ & Website: \\
\hline
\end{tabular}

